\title{
Effect of Vanadium and Carbon content on the Sinterability of Water Atomised High Speed Steel Powders
}

\author{
J.M.G. Mascarenhas ${ }^{1, a}$, M.M. Oliveira ${ }^{1, b}$, CS Wright $^{2, c}$ \\ ${ }^{1}$ INETI, DMTP, Estrada do Paço do Lumiar, 1649-038 Lisboa, Portugal \\ a joao.mascarenhas@ineti.pt; ${ }^{b}$ manuela.oliveira@ineti.pt \\ ${ }^{2}$ School of Engineering, Design \& Technology, University of Bradford, Bradford, UK, ${ }^{c}$ \\ c.s.wright@Bradford.ac.uk
}

Keywords: Sintering behaviour; Microstucture; Phase diagrams

\begin{abstract}
This paper presents the results of an investigation into the sintering behaviour of three vanadium enriched variants of T42 high-speed steel. Powders were prepared by water atomization with vanadium and carbon contents of 6-8 wt $\%$ and $2.2-2.7 \mathrm{wt} \%$, respectively. These were annealed, die pressed and sintered in vacuum. All three alloys were sintered to full density giving "as -sintered" microstructures comprising globular MC carbides dispersed in a martensitic matrix. Optimum sintering temperatures were in the range $1240-1250^{\circ} \mathrm{C}$ with lower optimum temperatures associated with higher carbon levels. Sintering characteristics are correlated with phase diagrams calculated using ThermoCalc ${ }^{\mathrm{TM}}$ software and TCFe2000 database. The implications for the design of sinterable vanadium containing high-speed steels are discussed.
\end{abstract}

Introduction: Supersolidus liquid phase sintering (SLPS) was demonstrated by Wright [1] as being the processes through which sintering of high speed steels (HSS) is carried out. In SLPS, prealloyed powders are heated to a temperature intermediate between the solidus and liquidus, Fig. 1. This method has been applied to a number of systems [2,3,4] including HSS [5,6,7,8,9].

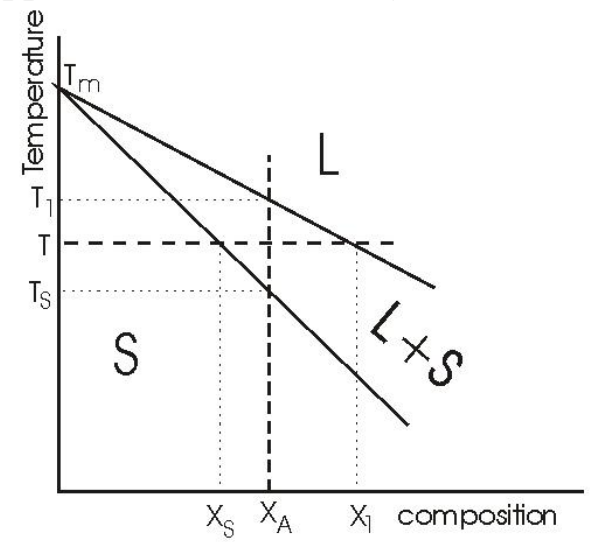

Fig. 1- Portion of binary phase diagram showing alloy composition and calculation parameters associated with heating a powder to temperature $\mathrm{T}$ between the liquidus and solidus curves.

The SLPS process is illustrated in Figure 2. At temperatures below the solidus line a small amount of solid state sintering produces inter particle bonding creating a skeletal structure. On crossing the solidus, liquid forms at interparticle necks, grain boundaries and, in powders with dendritic structures, within the inter dendritic spaces [10].

The compacts densify by a process of viscous flow arising from the capillary force the interparticle liquid exerts in the compact aided by the lubricating effect of the grain boundary liquid $[3,4,10]$. A critical amount of liquid is needed to promote full densification [4]. However, too much liquid leads to compact distortion. Optimal volume fraction of liquid is system specific [4] and maybe as little as $2 \%$ for T1 HSS [8], in excess of 5\% for M2 HSS [11] or in excess of $20 \%$ for a $\mathrm{Fe}-0.9 \% \mathrm{C}$ alloy [12]. 


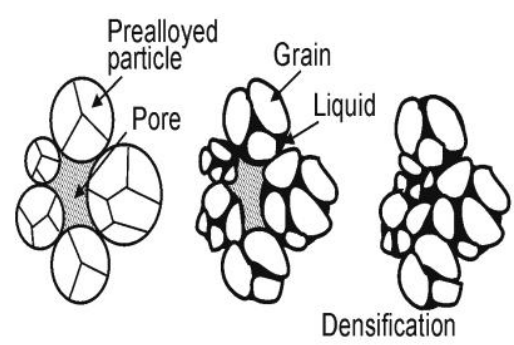

Fig. 2- Supersolidus liquid phase sintering (SLPS) schematic diagram. SLPS involves the formation of a liquid along the grain boundaries in powder, which leads to densification [2]

Fig. 3 shows schematically the sintering window -the temperature band over which acceptable microstructures (i.e. absence of coarse grain and carbide structures and continuous grain boundary carbide films) and properties can be obtained. $\mathrm{T}_{\mathrm{os}}$ is the temperature at which rapid densification occurs, $T_{m}$ being the temperature at which maximum density takes place and $T_{d}$ the distortion temperature.

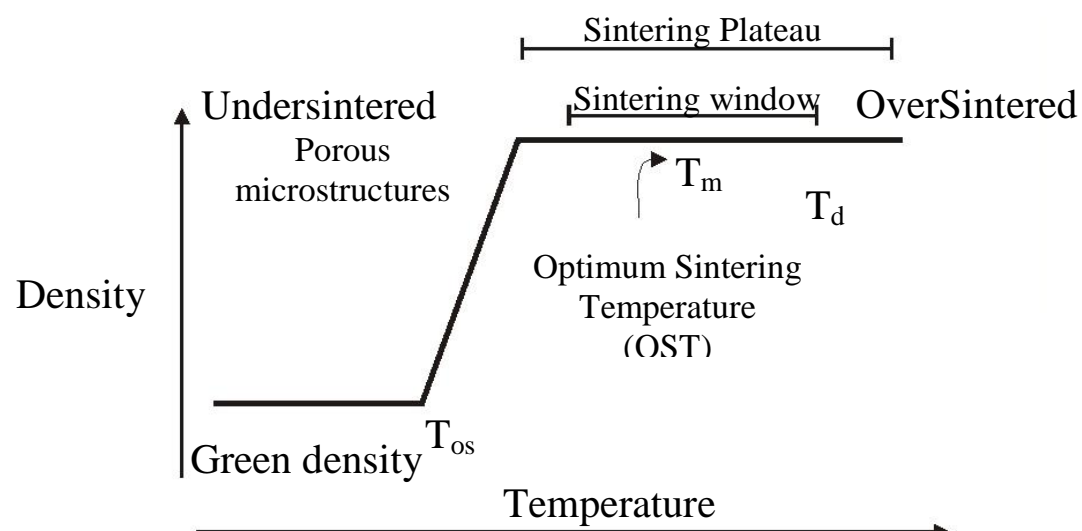

Fig. 3- Schematic representation of a sintering curve for a high speed steel powder

Experimental: Three prealloyed water atomised high-vanadium T42-type powders, P68, P77 and P81, were used in the present investigation (chemical compositions given in Table 1). The powders were produced at the Portuguese National Industrial Engineering and Technology Institute (INETI), using a $5 \mathrm{Kg}$ capacity Davy McKee water atomiser. The powders were used in the as-annealed condition, the annealing being performed in vacuum. Prior to annealing, dilatometric tests using a LK-02 ADAMEL device were performed in order to determine the respective powders' austenitising temperatures $(\alpha \rightarrow \gamma$ reaction). The annealing cycle was carried out in a GCA SUPER VII furnace. The annealing cycle consisted of heating at a rate of $10^{\circ} \mathrm{C} \mathrm{m^{-1 }}$ up to $950^{\circ} \mathrm{C}$, hold at this temperature until the vacuum was better than $10^{-2} \mathrm{~Pa}$, and controlled cooling from the austenitising temperature to $600^{\circ} \mathrm{C}$ at a rate of $2^{\circ} \mathrm{C} \mathrm{min}^{-1}$, and natural cooled onwards.

\begin{tabular}{|l|l|l|l|l|l|l|}
\hline Alloy & C & Cr & W & Mo & V & O \\
\hline P68 & 2.2 & 4 & 9.1 & 3.1 & 8.1 & 0.12 \\
\hline P77 & 2.7 & 4.4 & 9.2 & 3.7 & 7.2 & 0.12 \\
\hline P81 & 2.6 & 3.8 & 8.8 & 3.2 & 6.0 & 0.04 \\
\hline
\end{tabular}

Table 1-Chemical composition, wt\%, of annealed water atomised powders (Fe bal)

Differential thermal analysis (DTA) runs under argon protective atmosphere were carried out in order to determine solidus temperatures of the three alloys. The runs were performed in the temperature range $20-1350^{\circ} \mathrm{C}$, with both heating and cooling rates of $10^{\circ} \mathrm{C} \mathrm{min}^{-1}$. DTA results showed that the $\alpha \rightarrow \gamma$ transformation took place in the temperature range $840^{\circ}-900^{\circ} \mathrm{C}$. The determined solidus temperatures are $1138^{\circ} \mathrm{C}$ for $\mathrm{P} 77,1140^{\circ} \mathrm{C}$ for $\mathrm{P} 81$ and $1220^{\circ} \mathrm{C}$ for $\mathrm{P} 68$.

In order to investigate the carbon effect on sinterability, graphite additions of 0.1 (P68A) and 0.2 wt\% (P68B) were mixed with the P68 powder. 
Green compacts were produced, using the $<125 \mu \mathrm{m}$ powder fractions, by uniaxial compaction in rigid dies at a pressure of $800 \mathrm{MPa}$, giving densities of about $70 \%$ theoretical. Specimen dimensions were $22 \times 6 \times 5 \mathrm{~mm}^{3}$.

Vacuum sintering was performed using a GCA SUPER VII pilot scale furnace, under vacuum $\left(10^{-4} \mathrm{~Pa}\right)$. The preforms were heated at a rate of $10^{\circ} \mathrm{C} \mathrm{min}^{-1}$, soaked for one hour at the sintering temperature and then furnace cooled.

Results: Figure 4 shows sintering curves for P68, P77 and P81. The $T_{o s}, T_{m}$ and $T_{d}$ temperatures for the five alloys with and without graphite addition are shown in Table 2. In the case of P77 and P81 maximum density was attained at $1200^{\circ} \mathrm{C}$. As it can be seen from Figure 4, P77 and P81 alloys attained maximum densities at lower temperatures when compared to P68 alloy. Distortion temperatures of these two very alloys were $1250^{\circ} \mathrm{C}$, though $\mathrm{P} 81$ specimens showed higher distortion. Maximum density was attained at $1250^{\circ}, 1245^{\circ}$ and $1240^{\circ} \mathrm{C}\left(\mathrm{T}_{\mathrm{m}}\right)$ for $\mathrm{P} 68$, P68A and P68B respectively. In spite of P68A and P68B powders attained maximum density at lower temperatures when compared to P68, the sintering window had the same width for all the three powders, i.e. $10^{\circ} \mathrm{C}$. Distortion temperatures for those three alloys were $1280^{\circ}, 1270^{\circ}$ and $1260^{\circ} \mathrm{C}$ respectively.

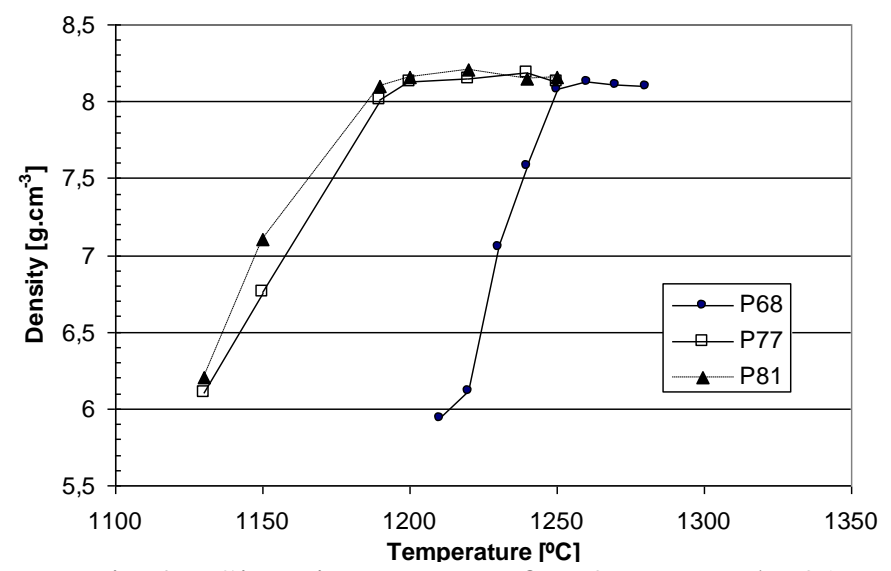

Fig.4 - Sintering curves of P68, P77 and P81

\begin{tabular}{|l|l|l|l|l|l|}
\cline { 2 - 6 } \multicolumn{1}{c|}{} & P68 & P68A & P68B & P77 & P81 \\
\hline $\mathbf{T}_{\mathbf{~} s}$ & 1220 & 1215 & 1210 & 1130 & 1130 \\
\hline $\mathbf{T}_{\mathbf{m}}$ & 1250 & 1245 & 1240 & 1200 & 1200 \\
\hline $\mathbf{T}_{\mathbf{d}}$ & 1280 & 1270 & 1260 & 1250 & 1250 \\
\hline
\end{tabular}

Table $2-\mathrm{T}_{\mathrm{os}}, \mathrm{T}_{\mathrm{m}}$ and $\mathrm{T}_{\mathrm{d}}$ Temperatures of the samples

Figure 5 shows the microstructures of P68 sintered at (a) $1260^{\circ}$ and (d) $1280^{\circ} \mathrm{C}$, this last one being the distortion temperature for this alloy; P77 and P81 sintered at $1200^{\circ}$ (b) and (c), and $1250^{\circ} \mathrm{C}$ (e) and (f), the last one being the temperature at which both alloys showed distortion. P68 showed globular shaped vanadium-rich MC carbides dispersed in a bainitic/martensitic matrix (600-700 $\mathrm{HV0.05)}$, up to $1250^{\circ} \mathrm{C}$. Globular tungsten-rich $\mathrm{M}_{6} \mathrm{C}$ carbides were also present in the specimens sintered up to $1210^{\circ} \mathrm{C}\left(\mathrm{T}_{\mathrm{os}}\right)$, their volume fraction decreasing with increasing temperature. For $\mathrm{T} \geq 1260^{\circ} \mathrm{C}$, an acicular shaped tungsten/molybdenum rich carbide could also be seen occasionally at grain boundaries. Its morphology and qualitative $\mathrm{x}$-ray analysis suggested that it was $\mathrm{M}_{2} \mathrm{C}$-type carbide. Above $1280^{\circ} \mathrm{C}$, incipient fusion caused the formation of needle-type molybdenum/tungsten rich eutectic carbides, as shown in Figure 5. Coarsening of MC carbides and prior austenite grain size was observed with increasing temperature for P68. P68A and P68B sintered specimens showed identical microstructures as P68, but shifted $10^{\circ}$ and $20^{\circ} \mathrm{C}$ downwards respectively.

The P77 and P81 alloys' microstructures exhibited similar features. Sintering at $1130^{\circ} \mathrm{C}$ both alloys exhibited uniform distributions of small $\mathrm{MC}$ and $\mathrm{M}_{6} \mathrm{C}$ carbides dispersed in the matrix. 
Up to sintering temperatures of $1190^{\circ} \mathrm{C}$ the microstructure consisted of MC type carbides with 1 to $3 \mu \mathrm{m}$ size dispersed in the matrix, and open porosity. At $1200^{\circ} \mathrm{C}, \mathrm{T}_{\mathrm{m}}$ temperature for both $\mathrm{P} 77$ and P81 alloys, the MC carbides ranged from 1 to $12 \mu \mathrm{m}$ and only residual porosity was observed. The matrix microhardness was in the range 495-565 HV0.05 for P77 and 505-580 $\mathrm{HV} 0.05$ for P81. At sintering temperatures of $1190^{\circ} \mathrm{C}$ and above the formation of acicular eutectic $\mathrm{M}_{2} \mathrm{C}$ carbides was observed. The volume fraction of $\mathrm{M}_{2} \mathrm{C}$ carbide, which was greater in the P81 specimens, increased with increasing sintering temperatures. This difference may be attributed to the higher carbon content of P81. Distortion temperature, $\mathrm{T}_{\mathrm{d}}$, was $1250^{\circ} \mathrm{C}$ for both alloys, with P81 distorting more than P77 specimens. This higher P81 distortion corresponds in the microstructure to a continuous $\mathrm{M}_{2} \mathrm{C}$ grain boundary eutectic carbide network, more extensive than in the P77 alloy. The MC carbides show a size range of 1 to $18 \mu \mathrm{m}$ and the usual globular shape.

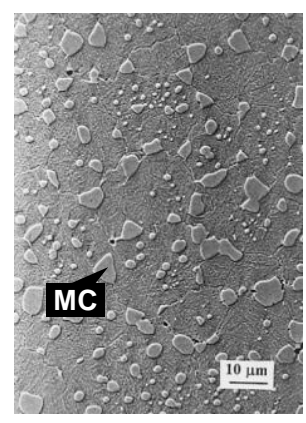

(a)

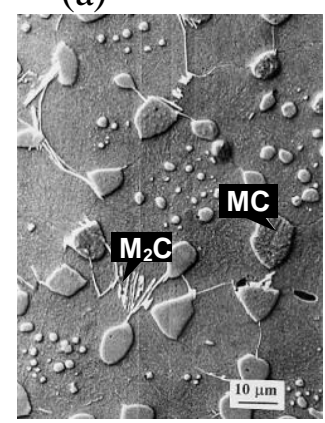

(d)

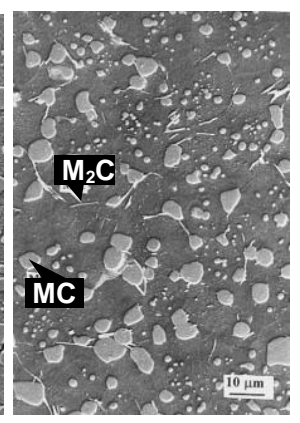

(b)

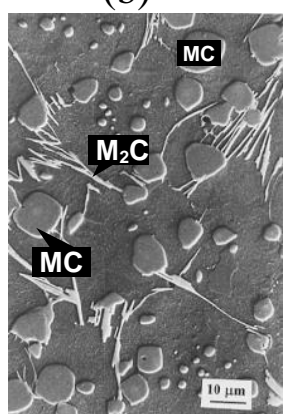

(e)

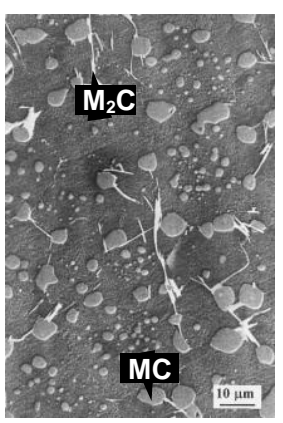

(c)

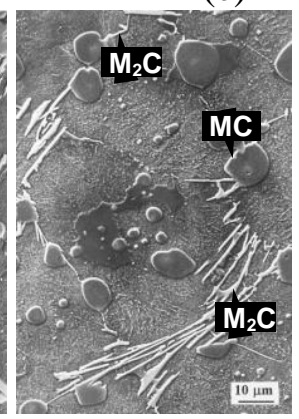

(f)

Fig. 5- Microstructures of the sintered specimens

(a) $\mathrm{P} 681260^{\circ} \mathrm{C}$; (b) $\mathrm{P} 771200^{\circ} \mathrm{C}$; (c) $\mathrm{P} 811200^{\circ} \mathrm{C}$; (maximum density) (d) $\mathrm{P} 681280^{\circ} \mathrm{C}$; (e) $\mathrm{P} 771250^{\circ} \mathrm{C}$; (f) $\mathrm{P} 811250^{\circ} \mathrm{C}$; (distortion temperatures)

Though the observed carbides present in the P68, P77 and P81 alloys were of the same type, i.e. $\mathrm{MC}, \mathrm{M}_{6} \mathrm{C}$ and $\mathrm{M}_{2} \mathrm{C}$, in the case of P77 and P81 alloys, it was not possible to attain maximum density without the presence of grain boundary $\mathrm{M}_{2} \mathrm{C}$ eutectic carbides. In fact, these $\mathrm{M}_{2} \mathrm{C}$ carbides were already observed in $\mathrm{P} 77$ and $\mathrm{P} 81$ specimens sintered at $1190^{\circ} \mathrm{C}$ and below.

Discussion: The vacuum sintering curves of P68, P77 and P81 powders, all exhibited the "S" shape sintering curve typical of sinterable water atomised HSS powders. Wright and co-workers $[7,1,8]$ have shown that vacuum sintering of water HSS as T1, M3/2 and M2 is an example of supersolidus liquid phase sintering (SLPS). In particular, Wright [1] has shown that the $\mathrm{T}_{\text {os }}$ temperature determined from sintering curves corresponds to the solidus temperatures determined by DTA. In fact, in P68, P77 and P81 vacuum sintered specimens, the observation of grain boundary $\mathrm{M}_{2} \mathrm{C}$ eutectic carbides in specimens sintered above $\mathrm{T}_{\mathrm{os}}$, and the fact that volume fraction of $\mathrm{M}_{2} \mathrm{C}$ eutectic increased concomitantly with sintering temperature, is indicative of sintering in the presence of a liquid phase whose volume fraction increased with sintering temperature.

Irrespective to microstructure, the main difference noted for the three alloys compared to other water atomised HSS powders in general, and high vanadium containing ones in particular, 
processed by vacuum sintering was the presence of solely globular vanadium rich MC carbides (and few $\mathrm{M}_{2} \mathrm{C}$ ) in specimens sintered at temperatures above $\mathrm{T}_{\mathrm{os}}$. In previous studies on $\mathrm{T} 42$ (3wt \% V), M3/2 (3wt\%V) [7], T15 (5wt\%V), ASP60 (6.5wt\%V) [5] and HITACHI (4.4wt\%V) [6], large angular $\mathrm{M}_{6} \mathrm{C}$ primary carbides have always be observed in addition to MC. In the case of P68, P77 and P81, $\mathrm{M}_{6} \mathrm{C}$ were only observed in the as-annealed powders, and in specimens sintered below $\mathrm{T}_{\mathrm{os}}$. However, $\mathrm{M}_{6} \mathrm{C}$ disappeared with increasing temperature as a consequence of dissolution, since it is known that the carbides begin to dissolve at temperatures above $1150^{\circ} \mathrm{C}$ [12], so that samples sintered between $T_{m}$ and $T_{d}$ contained no $M_{6} C$. The presence of $M C$ as the dominant carbide is simply due to the high vanadium content of these powders. It is known that vanadium is a strong carbide former ( $1 \mathrm{wt} \%$ vanadium having the same effect as $4 \mathrm{wt} \%$ of tungsten), which means that MC vanadium-rich carbides form preferentially. In fact, Fredriksson et al reported that for a M2-type $1.2 \mathrm{wt} \% \mathrm{C}$ alloy, above $1.9 \mathrm{wt} \% \mathrm{~V}$, the amount of MC carbide was almost proportional to the vanadium content. So, this same tendency of P68, P77 and P81 can be attributed to their high vanadium content.

Conclusions: The P68 composition could be vacuum sintered to full densities of $8.15 \mathrm{~g} \mathrm{~cm}^{-3}$ at $1260^{\circ} \mathrm{C}$, possessing acceptable microstructure comprising of vanadium rich MC carbides 1-20 $\mu \mathrm{m}$ in diameter embedded in a bainitic/martensitic matrix which possessed a prior austenite grain size of $<4-60 \mu \mathrm{m}$. Sintering window was found to be about $10^{\circ} \mathrm{C}$. Graphite additions of 0.1 and $0.2 \mathrm{wt} \%$ decreased optimal sintering temperatures to $1250^{\circ}$ and $1240^{\circ} \mathrm{C}$, respectively, though no broadening of the sintering window had been observed.

Higher carbon containing P77 and P81 alloys were found not to be vacuum sinterable due to the formation of deleterious to mechanical properties grain boundary $\mathrm{M}_{2} \mathrm{C}$ eutectic carbides. These carbides were present in specimens undersintered at $1190^{\circ} \mathrm{C}\left(8 \mathrm{~g} / \mathrm{cm}^{-3}\right)$. The sintering difficulty of high-vanadium containing HSS observed in the present research was attributed, accordingly to both experimental observations and computer calculated phase diagrams, to the constriction of the $\mathrm{L}+\gamma+$ carbides region where sintering is carried out.

\section{References}

1. C.S. Wright, Role of Molybdenum in Promoting Densification During Vacuum Sintering of T1 Grade High Speed Steel Powders, Powder Metallurgy, 32(2),1989,114-117

2. Randall M. German, Powder Metallurgy Science, Metal Powder Industries Fed., 1984

3. Yixiong Liu, Rajiv Tandon and Randall M. German, Modelling of Supersolidus Liquid Phase Sintering: I. Capillary Force, Metallurgical and Materials Transactions, 26A,1995

4. Yixiong Liu, Rajiv Tandon and Randall M. German, Modelling of Supersolidus Liquid Phase Sintering: II. Densification, Metallurgical and Materials Transactions, 26A, 1995

5. M.M. Oliveira, J. Mascarenhas and A.S. Wronski, Supersolidus Sintering and Mechanical Properties of Water Atomised Fe-2.3C-4.0Cr-7.0Mo-10.5Co-6.5V-6.5W High Speed Steel, Powder Metallurgy, 36 (4),1993, 281-287

6. M.M. Oliveira, O.Sousa Ribeiro, A.S. Wronski, Processing of a High-Alloy High-Speed Steel Via Water Atomisation and Direct Sintering, PMI, 25,(5),1993, 215-218

7. C.S. Wright and B. Ogel, Supersolidus Sintering of High Speed Steels, Part I: Sintering of Molybdenum Based Alloys, Powder Metallurgy, 36 (3), 1993, 213-219

8. C.S. Wright, B. Ogel, F. Lemoisson and Y. Bienvenu, Supersolidus Sintering of High Speed Steels Part 2 : Sintering of Tungsten Based Alloys, Powder Metallurgy, 1995, 221-229

9. C.S. Wright, A.S. Wronski, M.Durand-Charre, I. Ansara, Y. Bienvenu, F. Lemoisson, M.M. Oliveira and J. Mascarenhas, Supersolidus Sintering of High Speed Steels - The Computer Aided Design of Highly Sinterable Alloys, Proc. PM'94, Paris, 1994, 1517-1520

10. R.M. German, A Quantitative Theory for Supersolidus Liquid Phase Sintering, Powder Metallurgy, 34(2), 1991, 101-107

11. Shigeaki Takajo and Minoru Nitta, Observation of Liquid Phase Sintering of a High Speed Steel Powder, Sintering '85, Plenum Press, 1987, 189-196

12. (117)- J.A. Lund and S.R. Bala, Supersolidus Sintering, Modern Developments in Powders Metallurgy, $\underline{6}, 1974,409-421$ 